\title{
CURRÍCULO INTEGRADO NA MODALIDADE EJA: A Pedagogia de Projetos no Proeja
}

\author{
Telma Alves ${ }^{1}$
}

\begin{abstract}
RESUMO
Este trabalho apresenta o recorte do material empírico coletado numa investigação, realizada de 2014 a 2018, cujos sujeitos são professores das áreas de Ciência e Matemática e de Informática do curso técnico médio integrado de Manutenção e Suporte em Informática, na modalidade de Educação de Jovens e Adultos. O texto analisa as percepções dos próprios professores a respeito do trabalho docente realizado no curso, destacando, dentre outros aspectos, a materialização do currículo integrado por meio dos denominados Projetos Integradores. Pela abordagem qualitativa, na forma de estudo de caso, foram realizadas entrevistas, inspiradas no método compreensivo, como meio de alcançar a percepção que os sujeitos têm sobre tal concepção. O referencial teórico apoia-se em autores da Pedagogia Histórico-Crítica e dos Saberes Docentes, cujas ideias se complementam. Dentre os resultados obtidos, destacamos, neste texto, como os sujeitos percebem a materialização do currículo integrado. Pela análise de conteúdo das entrevistas, identificam-se avanços e possibilidades na fundamentação dos Projetos Integradores, levando em conta o contexto complexo e real.
\end{abstract}

Palavras-chave: Currículo Integrado. Proeja. Educação profissional. Educação de Jovens e Adultos.

INTEGRATED CURRICULUM IN EJA (YOUTH AND ADULT EDUCATION): THE PEDAGOGY OF PROJECTS IN THE PROEJA

\section{ABSTRACT}

This paper presents the excerpt of the empirical material collected in an investigation, conducted from 2014 to 2018 , whose subjects are teachers of Science and Mathematics and Informatics areas of the integrated technical course of Maintenance and Support in Informatics, in the modality of Youth and Adult Education. The text analyzes the teachers' own perceptions about the teaching work done in the course, highlighting, among other aspects, the materialization of the integrated curriculum through the so-called Integrator Projects. Through the qualitative approach, as a case study, interviews were conducted inspired by the comprehensive method, as a means of achieving the perception that the subjects have of their work. The theoretical framework is based on authors of the Historical-Critical Pedagogy and Teaching Knowledge. Among the results obtained, we highlight in this text how the subjects perceive the materialization of the integrated curriculum. By analyzing the content of the interviews, advances and possibilities are identified in the foundation of the Integrating Projects, taking into account the complex and real context.

Keywords: Integrated Curriculum. Proeja. Professional Education. Youth and Adult Education.

Recebido em: $14 / 3 / 2020$

Aceito em: $17 / 4 / 2020$

\footnotetext{
${ }_{1}$ Professora do Instituto Federal de Educação, Ciência e Tecnologia do Rio de Janeiro (IFRJ). Doutora em Educação pela Faculdade de Educação da Universidade Federal Fluminense (Feuff). http://lattes.cnpq.br/9175645176876330. https://orcid.org/0000-0002-7867-0907. telma.alves@ifrj.edu.br
} 
No Brasil, entre 1990 e 1994, o atendimento do governo federal à Educação de Jovens e Adultos (EJA) foi marcado pela descontinuidade, com ações de alfabetização ${ }^{2}$ que não tinham recursos garantidos e pelo recuo do Estado no atendimento a esse campo educacional. Nesse mesmo período, no entanto, segundo Machado (1998), o movimento de educadores tenta um fortalecimento da discussão para construir um programa sistemático não só de alfabetização, mas também para o Ensino Fundamental de Jovens e Adultos. Ao mesmo tempo, já vinham acontecendo as discussões para o projeto da Lei de Diretrizes e Bases da Educação Nacional (LDBEN).

Os debates realizados a partir de 1988 resultam na inserção da EJA como modalidade do ensino regular na LDBEN de 1996 e entendida como direito. Para que tal direito se efetive, há a necessidade da superação de concepções conservadoras e compensatórias, tais como desconsiderar as experiências de vida dos sujeitos que retornam à escola, recuperar o tempo "perdido" ou o conteúdo não dado. Enquanto existir qualquer resquício dessas concepções, o direito, definido na letra da lei, não sendo benefício ou favor, fica comprometido.

A construção coletiva do movimento de educadores, todavia, foi desconsiderada e as diretrizes para a EJA foram reduzidas, na LDBEN no 9.394/96, a dois artigos. $O$ artigo no 37, que assegura a educação escolar pública aos jovens e adultos e confere à EJA a concepção de modalidade da educação básica, o que representa uma reconfiguração do campo e a afasta da ideia de ensino supletivo; e o artigo no 38, que reduz as idades para os exames de certificação que recebem o nome de exames supletivos. Ao estabelecer as idades de 15 anos para a certificação do Ensino Fundamental II e de 18 anos para a certificação do Ensino Médio, estão estabelecidas, implicitamente, as condições de correção de fluxo e aceleração do processo educacional para essas duas etapas da educação básica.

Em 1997 o governo exarou o Decreto $\mathrm{n}$ - 2.208/97, que visava a regulamentar a LDBEN no 9.394/96, e, atendendo às prescrições neoliberais, foi o norteador da reestruturação do ensino técnico e profissional (EP) que, de acordo com seu artigo 5으, passa a ter organização independente do Ensino Médio. Os anos que se seguiram nas instituições da Rede Federal de Educação Profissional e Tecnológica, até a revogação desse decreto em 2004, foram de muita tensão e disputa.

A derrota do projeto de LDBEN, apresentado pelos variados setores progressistas, seguida da promulgação do Decreto no 2.208/97, que determinou a separação do ensino profissional do Ensino Médio, deflagrou o processo de debates durante o ano de 2003, que culminou na aprovação do Decreto no 5.154/04 (FRIGOTTO; CIAVATTA; RAMOS, 2005). O Decreto no 5.154/04, em seu artigo 3ㅇ, indica a organização dos cursos de acordo com itinerários formativos, como forma de "superar a oferta fragmentada e descontínua de formação profissional que não redundava em créditos para os trabalhadores, seja para fins de exercício de uma ocupação, seja para o prosseguimento de

Plano Nacional de Alfabetização e Cidadania (PNAC); Plano Decenal de Educação para Todos (DI PIERRO, 1992). 
estudos" (FRIGOTTO; CIAVATTA; RAMOS, 2005, p. 40). Ao encontro da preocupação com a escolaridade e a qualificação profissional, o decreto indica que os cursos contemplem a modalidade de EJA.

Esse contexto, caracterizado pelas ações do governo Fernando Henrique Cardoso (FHC), pelas reações dos diversos setores da sociedade, pela retomada do debate sobre o Ensino Médio e a educação profissional pelos atores do campo do Trabalho e Educação, pelo movimento sindical e pelo governo instalado a partir de 2003, faz com que o Programa de Integração da Educação Básica à Educação Profissional na modalidade Educação de Jovens e Adultos - Proeja - seja entendido como uma conquista. Esse intenso processo de mobilização visou à criação de políticas que superassem a ideia de curso supletivo e que integrassem a modalidade EJA no sistema educacional de nível médio e fundamental (FRIGOTTO; CIAVATTA, 2011). Procedendo assim, estou tratando o fenômeno educativo como totalidade, buscando entender o contexto histórico no qual ocorrem os movimentos, as ações e/ou as propostas educacionais.

As instituições da Rede Federal de Educação Profissional e Tecnológica, em 2005, foram convocadas a instituir o Proeja, enquanto programa de governo, pela experiência na educação profissional e pela qualidade dos cursos oferecidos. A mesma Rede Federal, no entanto, assim como seus professores, apresentava quase nenhuma experiência com a modalidade EJA.

O breve histórico descrito, somado ao fato de as instituições federais, consideradas de elite, passarem a receber trabalhadores, historicamente apartados do sistema educacional, motivaram a realização, entre 2014 e 2018, da investigação, em nível de Doutorado, cujo objeto de estudo foi o trabalho docente de 11 professores no curso técnico de Manutenção e Suporte em Informática, doravante denominado Proeja/MSI, que atende à instalação do Proeja no Campus Rio de Janeiro do Instituto Federal de Educação, Ciência e Tecnologia do Rio de Janeiro (IFRJ).

A pesquisa de abordagem qualitativa, na forma de estudo de caso, visou a compreender especificidades do trabalho docente, bem como identificar percepções, pela voz dos próprios professores, a respeito da materialização da Pedagogia de Projetos, na qual se sustenta o Projeto Político Pedagógico do curso Proeja/MSI, por meio dos denominados Projetos Integradores.

Ao longo deste texto vamos apresentar as principais ideias que ancoraram nosso estudo, bem como um recorte do material empírico com as análises e, finalmente, proceder às conclusões.

\section{CONCEPÇÕES SOBRE AS MODALIDADES EDUCAÇÃO DE JOVENS E ADULTOS (EJA) E EDUCAÇÃO PROFISSIONAL (EP)}

Na história da EJA, segundo Julião (2012), três fases se sucedem: a da garantia do direito, a que se refere às concepções de educação e a da diversidade. Aqui, vou lançar luz sobre a segunda fase.

Se pensarmos na EJA como preparação para o trabalho, estamos assumindo uma educação como instrumentalização, treinamento ou adequação de mão de obra para o mercado. Precisamos nos afastar, porém, de uma "educação exclusiva" (FERNANDES, 
1991, p. 48). O pensamento "É trabalhador? Então vai ser operário, ele precisa de uma educação técnica, precisa ser instruído, não educado; ele precisa ser adestrado, não polido" (FERNANDES, 1991, p. 48), está enraizado nas propostas de escolarização para adultos. Fernandes (1991) afirma, ainda, que "o trabalhador precisa conhecer o mundo, explicar o mundo, transformar o mundo e, para isso, não basta [...] adestramento na situação de trabalho, a escolaridade técnica" (p. 49). Relacionamos essa afirmativa à compreensão da educação "como parte essencial de um processo com múltiplas determinações, e não como chave mágica que promove a inclusão na sociedade de mercado, em que a competitividade e o individualismo se impõem como valores supremos" (FÁVERO; RUMMERT; DE VARGAS, 1999, p. 46).

Se imaginarmos a educação como formação de sujeitos cidadãos, somos levados a refletir sobre ela do ponto de vista da cidadania, que, segundo Alves (2010), nos "remete à configuração de projetos de sociedade, em que se designa um certo lugar para a educação" (p. 153). Freire (2000) afirma que "a capacidade de observar, de comparar, de avaliar para, decidindo, escolher, com o que, intervindo na vida da cidade, exercemos nossa cidadania, se erige como uma competência fundamental" (p. 33). Ao encontro dessas ideias, cada sujeito pode adquirir, pela educação, a capacidade de ler o mundo e interpretá-lo e pode construir um projeto de sociedade não excludente e solidária.

Todos estamos inseridos num processo de construção em que produzimos nossa história e a do mundo no qual estamos inseridos. Ser cidadão é atuar no mundo, lutando pela própria dignidade, consciente da historicidade que estabelece um caminho aberto para a mudança (ALVES, 2010).

Paulo Freire ganhou destaque nos anos 60 do século 20, quando propôs um paradigma pedagógico próprio para a alfabetização de adultos, de modo a "realizar uma educação de adultos crítica, voltada à transformação social, e não apenas à adaptação da população a processos de modernização conduzidos por forças exógenas" (DI PIERRO; JOIA; RIBEIRO, 2001, p. 60). Paulo Freire, ao localizar o sentido da educação na compreensão do mundo, na conscientização, passa a dialogar com as pessoas e com as suas vidas. Por essa concepção, os conteúdos são carregados de significado político e levam à conscientização das condições em que o sujeito está imerso. A pedagogia crítica de Paulo Freire baseia-se em um processo dialético de produção do conhecimento que parte do dado empírico (concreto real), que é teorizado (apropriado pelo pensamento abstrato) e chega ao concreto (real concreto ou real criticado) para, então, transformá-lo (SAVIANI, 2013).

O pensamento de Paulo Freire extrapolou a ação educadora de alfabetização e tornou-se base teórica para escolarização de jovens e adultos, no sentido de uma educação emancipatória e de não conformação à sociedade, muitas vezes tida como impossível de ser mudada em virtude do discurso ideológico da inviabilização do possível (FREIRE, 2000).

A Educação Profissional (EP), que inicialmente tinha como objetivo atender aos filhos dos membros das parcelas menos favorecidas da sociedade, passou por algumas mudanças ao longo do tempo por meio das legislações. Segundo Frigotto (2011), as Leis 
Orgânicas do Ensino, na década de 40 do século 20, conferem caráter estrutural à dualidade entre o ensino para aqueles que vão comandar o país e aqueles que vão compor a classe trabalhadora.

A forma de organização social, política e econômica, desde a década de 40, reproduziu no Ensino Secundário, atual Ensino Médio, a ruptura entre o ensino dos conhecimentos historicamente construídos pela humanidade - propedêutico - para as elites e o ensino do aprender a fazer - técnico. Nos anos 90, essa ruptura foi reforçada por dois argumentos do Banco Mundial. De um lado, o aumento da extinção de postos de trabalho pela mudança do paradigma técnico para o paradigma tecnológico não justificava gastos com educação profissional; de outro, a maioria da população, composta por pobres, negros, minorias étnicas e mulheres, não era considerada capaz de exercer atividades intelectuais, por isso seria desperdício investir em educação propedêutica (KUENZER, 2000).

Para a educação nos anos seguintes ao Ensino Fundamental, o Estado apropria-se do conceito de equidade, não no sentido de reduzir as desigualdades, mas, sim, no sentido de adequar o ensino às diferenças, entendidas como dons naturais, ou, na compreensão de Bourdieu (2015), o capital cultural individual, que determina as trajetórias (KUENZER, 2000). A dualidade histórica entre o Ensino Médio e a Educação Profissional tornava-se mais acentuada.

Além de outros documentos, as Diretrizes Curriculares para o Ensino Médio (1998) e as Diretrizes Curriculares Nacionais para a Educação Profissional de Nível Técnico (1999), são significativas para compreendermos o significado da educação no contexto das reformas preconizadas pelos organismos internacionais. Os princípios dessas diretrizes baseadas em competências, apoiavam-se nos alicerces apresentados pelo Relatório Jacques Delors (DELORS et al., 2010), segundo os quais as necessidades de aprendizagem são: aprender a conhecer, aprender a fazer, aprender a conviver e aprender a ser. No relatório de Delors "a principal finalidade da educação contemporânea seria a formação de personalidades flexíveis para adaptação à realidade instável e incerta" (CIAVATTA; RAMOS, 2012, p. 18).

Nos anos 90 do século 20, a reforma que atingiu a rede federal foi um retrocesso na construção/consolidação da proposta do Ensino Médio integrado (EMI). O EMI é uma concepção de Ensino Médio fundada em uma formação profissional que se insira nas mudanças de base técnica da produção e que, ao mesmo tempo, seja emancipatória, de forma que seja superada a ideia de "formação profissional como adestramento e adaptação às demandas do mercado e do capital” (FRIGOTTO; CIAVATTA; RAMOS, 2005, p. 15).

Faz parte do processo educativo romper com o mito de que uma formação técnica garante vaga no mercado de trabalho, pois ele está ligado a variáveis mais complexas do que a aquisição de competências e habilidades individuais.

O projeto de EMI busca ultrapassar o dilema colocado para a escola, traduzido em duas opções que se excluem: formação para a cidadania ou para o trabalho produtivo. Frigotto, Ciavatta e Ramos (2005) o qualificam como um processo histórico necessário na construção da escola unitária e politécnica, a qual, porém, necessita de "mudanças estruturais na sociedade" (p. 15). Na mesma linha de pensamento, Marise Ramos 
(2011, 2012) nos apresenta discussões sobre o currículo integrado como contribuição à superação de um currículo voltado para as humanidades ou para a ciência e a tecnologia.

A escola exerce a tarefa de socializar os conceitos já elaborados sobre a realidade para que o movimento de construção do conhecimento novo ocorra por intermédio de possibilidades da percepção das múltiplas relações que caracterizam a totalidade (RAMOS, 2012).

Para jovens e adultos, no entanto, "o sentido do conhecimento não está em proporcionar, primeiro, a compreensão geral da vida social e, depois, instrumentalizá-las para o exercício profissional" (RAMOS, 2011, p. 777). Por muitas vezes, o retorno dessa parcela da população aos bancos escolares se dá pela necessidade de se inserirem no mundo do trabalho e produzirem sua subsistência. Então, há o desafio específico de se tentar superar que a formação profissional seja vista, no caso do Proeja, pelos estudantes que o procuram, como garantia de ingresso e permanência na atividade produtiva.

Neste sentido, é importante que os estudantes da EJA sejam compreendidos como sujeitos de conhecimento que trazem para o interior da instituição escolar as suas experiências de vida, uma vez que, mais velhos ou mais jovens, eles têm "a vivência profissional, social e pessoal (aí incluída a vivência escolar anterior) [...] e estratégias construídas e/ou adquiridas nas leituras que vêm fazendo de mundo e de sua intervenção nele" (FONSECA, 1998 , p. 81-82).

Ao mesmo tempo que Blum e Zanardini (2011) consideram que o Proeja se caracteriza em conformar a classe trabalhadora ao novo modelo de produção, por oferecer formação geral de modo a que jovens e adultos se adaptem ao movimento do mercado flexibilizado, também afirmam que ele "se coloca como um meio desses jovens e adultos absorverem os conhecimentos elaborados historicamente pelo homem" (p. 209). É nessa perspectiva dialética que é possível pensar num trabalho docente que não reproduza o sistema, mas que possibilite caminhos para a transformação.

\section{PROJETOS INTEGRADORES: Possibilidade Para o Currículo Integrado}

Para pensarmos a modalidade EJA, inserida na atual Rede Federal de Educação Profissional, Científica e Tecnológica, Ventura (2011, p. 93) assevera que:

O desafio histórico da EJA continua sendo o de romper com o caráter compensatório e assistencialista na educação de jovens e adultos trabalhadores (denominados de desvalidos, pobres, excluídos, em risco social, etc.). Ao mesmo tempo, na perspectiva contra-hegemônica, o desafio é avançar na luta pela superação da dualidade estrutural da educação brasileira.

A dualidade estrutural pode ser percebida, tanto entre os professores quanto entre os estudantes do Proeja/MSI, pela prevalência da parte técnica sobre a formação geral, o que mostra um viés tecnicista em detrimento da formação humana. Acrescente-se o que nos ensinam Kuenzer e Grabowsk (2016) e Romão (2011), sobre as mudanças no sistema produtivo, da base eletroeletrônica para a base microeletrônica, reconfigurarem essa dualidade e requererem uma nova proposta de educação. 
A construção do Projeto Pedagógico para instalação do curso Proeja/MSI aconteceu num contexto de transição entre concepções diferentes de Ensino Médio, educação profissional e com a retomada do debate sobre a dualidade entre os cursos propedêuticos e técnicos, de acordo com Frigotto, Ciavatta e Ramos (2005).

Analisando o documento Projeto Político Pedagógico ${ }^{3}$ do curso Proeja/MSI, percebe-se que o embasamento teórico não trata da dualidade estrutural do Ensino Médio, além de propor projetos interdisciplinares para a construção de conhecimentos significativos. "Ao estabelecer a relação entre as disciplinas em atividades e projetos de estudo" (ALVES, 2018b, p. 150), o Projeto Político Pedagógico do curso Proeja/MSI reduz a interdisciplinaridade a recurso didático (RAMOS, 2011).

Se por um lado é possível que os envolvidos na efetivação do curso Proeja/MSI tenham encontrado dificuldades em compreender a proposta metodológica do Proeja, como nos mostram Escandiel Crizel, Greff Passos e Del Pino (2014) sobre a implantação do Proeja no campus Bagé do então Cefet-BG, por outro identifica-se um esforço em construir um modelo pedagógico próprio.

O grupo, formado por professores e outros profissionais da área pedagógica, optou pela Pedagogia de Projetos como maneira de materializar o currículo integrado, e, em acordo com os fundamentos ${ }^{4}$ enunciados pela Resolução no 03/98, o Projeto Pedagógico do Proeja/MSI é assentado na Pedagogia de Projetos, e afirma que:

A Pedagogia de Projetos é uma mudança de postura pedagógica fundamentada na concepção de que a aprendizagem ocorre a partir da resolução de situações didáticas significativas para o aluno, aproximando-o o máximo possível do seu contexto social, através do desenvolvimento do senso crítico, da pesquisa e da resolução de problemas (BRASIL, 2007, p. 7).

Embora o texto do Projeto Político Pedagógico remeta à pedagogia das competências, a ausência de

Uma descrição mais detalhada sobre a interdisciplinaridade abre uma possibilidade para que, na prática pedagógica concreta, os educadores possam relacionar esse princípio à reconstituição da totalidade histórica dos conhecimentos produzidos pela humanidade, através da inter-relação dos conceitos oriundos dos diversos campos da ciência (ALVES, 2018a, p. 237).

A prática pedagógica concreta dos professores, munidos de perspectiva crítica, pode desenvolver projetos ${ }^{5}$ que permitam a apropriação de ferramentas intelectuais a fim de elaborar leituras mais complexas do mundo (ALVES, 2010). Este foi o pensamento que me motivou a investigar se existiam discussões que permitissem ao professor, em suas condições de trabalho, construir um clima de liberdade intelectual.

\footnotetext{
3 Para aprofundar a análise do documento consultar Alves (2018a).

4 A estética da sensibilidade, a política da igualdade e a ética da identidade são, segundo Ramos (2011), "uma releitura das quatro grandes necessidades de aprendizagem relatadas na Reunião Internacional sobre Educação para o Século XXI da Unesco: aprender a conhecer, aprender a fazer, aprender a conviver e aprender a ser" ( $p$. 774).

A título de exemplo desta afirmação, ver o trabalho de Alves; Souza de Almeida, Almeida (2019).
} 
Nos pressupostos teóricos metodológicos da proposta curricular para o Proeja/ MSI, construídos em 2007, foi explicitado que a articulação entre a formação técnica e a formação geral seria efetivada "através da integração do conhecimento científico, tecnologia e mundo social. Serão abordados, em conjunto, os conteúdos científicos e tecnológicos, sob aspectos históricos, éticos, políticos e socioeconômicos" (BRASIL, 2007, p. 11).

A contradição entre a explicitação do objetivo de desenvolver competências e habilidades relacionadas às técnicas produtivas e à solução de problemas, e a enunciação da preocupação com os aspectos históricos, culturais e humanísticos, torna possível, pela prática pedagógica concreta, a superação da dicotomia entre formação básica e formação técnica (ALVES, 2018b).

A proposta de desenvolver projetos integradores, que diferenciou o Proeja/MSI dos outros cursos técnicos integrados, estabelecia a realização de reunião semanal da equipe para discussão pedagógica e condução dos projetos integradores que atendiam à Pedagogia de Projetos. No primeiro ano do curso, os projetos integradores eram desenvolvidos durante as reuniões semanais. Depois, com o aumento da carga horária do curso, foi possível instituir uma disciplina denominada Projeto Integrador, informalmente chamada de PI. Este trabalho apresenta o recorte do material empírico coletado que se relaciona à compreensão de como essa concepção pedagógica veio se materializando no período da investigação.

\section{METODOLOGIA}

Cabe, neste ponto, caracterizar o locus da investigação. O campus Rio de Janeiro, do Instituto Federal de Educação, Ciência e Tecnologia do Rio de Janeiro (IFRJ), tem, assim como a atual Rede Federal de Educação Profissional, Científica e Tecnológica, ${ }^{6}$ um longo percurso histórico de transformações. Durante 13 anos o campus foi a sede própria da instituição denominada Escola Técnica Federal de Química (ETFQ), que, à época, com recursos físicos e humanos adequados, tinha como função reproduzir o arbitrário cultural necessário para formar técnicos de nível médio, e, assim, atender o desenvolvimento das indústrias, que interessava à economia desde a década de 40. Em seguida, passou a ser unidade descentralizada (Uned), quando houve, em 1999, a transformação para Centro Federal de Educação Tecnológica (Cefet), que possibilitava a abertura de cursos superiores, e desde 2009 tornou-se mais um dos diversos campi do IFRJ. 0 campus Rio de Janeiro do IFRJ pode ser considerado um sistema amplo, com diversas unidades propensas a estudos qualitativos.

Para alcançar o objetivo geral de analisar desafios teórico-práticos do trabalho docente, elegemos a abordagem qualitativa, na forma de estudo de caso, no qual o trabaIho docente dos 11 professores dentro desse curso técnico, especificamente, é tratado como um todo. Neste estudo, as entrevistas, inspiradas no método compreensivo (KAUFMANN, 2013), foram a estratégia dominante, pois o objetivo era a coleta de dados descritivos na linguagem dos professores, de modo a compreender a forma como os pro-

A atual Rede tem sua origem na criação, por Nilo Peçanha, em 1909, de 19 Escolas de Aprendizes e Artífices. A ETFQ, porém, não fazia parte desse conjunto, pois foi criada em 1942. Para mais detalhes consultar Alves (2018b). 
fessores interpretavam o Proeja/MSI e o próprio trabalho docente (BOGDAN; BIKLEN, 1994). Pela análise de conteúdo (BARDIN, 2016) das entrevistas foi possível eleger as unidades de análise e proceder à categorização. Da quarta ${ }^{7}$ unidade de análise denominada "trabalho docente no Proeja/MSI" emergiram três categorias, quais sejam: "escolhas no processo de ensino", "pedagogia de projetos" e "desafios e especificidades". Neste texto, apresentamos os resultados e as análises que dizem respeito à categoria "pedagogia de projetos". Os professores, ao enunciarem suas percepções do que vivenciam, inauguram discussões entre teoria e prática tão necessárias ao trabalho docente. A amostra é composta de 11 professores, sendo 2 de Física, 2 de Química, 3 de Matemática e 4 da área de Informática que lecionam disciplinas diversas. A discussão trazida neste trabalho foi possível pelos relatos de 3 professores (as): 2 de Informática, 1 de Física e 1 de Matemática sobre a experiência de trabalhar com a disciplina de projeto integrador (PI).

\section{RESULTADOS E DISCUSSÕES}

O professor Hórus ${ }^{8}$ nos explica sua compreensão sobre o PI da seguinte forma:

Essa questão de ser integrador é a questão de eu poder, é passear em todas as áreas, e, com a ideia que foi formulada, eu conseguir pegar as ajudas de cada, de cada área para que possam agregar valor ao meu projeto; então, a turma em si, quando vai fazer, ela tem nesse produto, ela tem alguma entrega escrita, alguma entrega de cálculo, alguma coisa que foi pesquisada antes para que ajude isso; dependendo da pesquisa, ela vai ter Biologia, Química, Física envolvida nisso; então, é História, Geografia, dependendo do que eles vão fazer do eixo tecnológico que eles vão usar, é, eles vão precisar disso; então, eu vejo que tem muito professor que orienta, mas fica só naquele mundinho; ele não sai daquele mundinho, mas eu tenho que fazer com que os alunos procurem outras áreas também, né, procurar outras áreas se torna difícil porque o próprio aluno fica o que, ele não tem tempo para isso [...] (1\%/6/2017).

A busca, realizada pelos alunos e orientada pelo professor, por conhecimentos diversos para desenvolver projetos, remete à ideia de exercício da cidadania, uma vez que requer reflexões, escolhas e decisões (FREIRE, 2000; ALVES, 2010).

Ele percebe uma perda no tempo reservado para o diálogo da equipe que trabaIha no Proeja/MSI. Em algum momento houve a perda dos encontros semanais para discutir sobre tudo. Esses encontros passaram a ser mais espaçados e tratar de questões imediatas e não das discussões pedagógicas.

A professora Juno (em 20/2/2017) nos informou que não sabia o que era o $\mathrm{PI}$, que "não tinha entendido o que estava acontecendo no Proeja" e que não tinha como participar das reuniões, pois no horário da reunião da equipe do Proeja/MSI estava lecionando em outro curso. Mesmo assim, ao descobrir que o tema do PI estava "relacionado a pilhas ou descarte de pilhas", ela tentou integrar sua disciplina da seguinte forma:

\footnotetext{
As quatro unidades de análise foram: "o percurso de vida até à docência", "a formação profissional/formação pedagógica", "a experiência entendida como os saberes das ações pedagógicas", "o trabalho docente no Proeja/ MSI";

Esse e os demais nomes são fictícios.
} 
[...] eles estavam aprendendo porcentagem. Aí eu coloquei, fiz umas questões, eu vi que tinha um programa do Santander que recolhia pilhas para levar para o descarte correto [...] aí eu peguei dados desse programa e tal para gente fazer o trabaIho. Mas assim, aquela coisa que, poxa, eu fiquei lá me esforçando, pesquisando o negócio sobre pilha, que teoricamente eu não precisava fazer isso, eu podia botar uma questão qualquer de porcentagem, né. Mas eu vi que eles estavam estudando sobre isso, eu lembro que eu pesquisei e tal e fiz um materialzinho com aquilo (Prof. a Juno, 20/2/2017).

Essa situação vivenciada por Juno representa e sintetiza a preocupação trazida na investigação empreendida, qual seja: a importância do diálogo entre os professores que trabalham no curso para que seja possível o desenvolvimento da proposta pedagógica eleita pela equipe de instalação do curso no sentido de materializar a educação profissional integrada ao Ensino Médio na modalidade EJA. Foi possível perceber que muitas perdas ocorrem no trabalho docente, quando não há possibilidade de ocorrerem as discussões coletivas. Autores como Pimenta (1999) e De Vargas e Fantinato (2011) sinalizam a importância e a necessidade, o que foi possível identificar no relato dos professores, de tais reuniões. Essas perdas, sob meu ponto de vista, vão desde a consciência da participação do professor no processo (sentido) e a identificação de suas opções, de suas decisões e seus saberes na execução de suas tarefas em sala de aula e na escola (significado), até a integração dos conhecimentos de base científica e cultural, humanista e tecnológica com a formação profissional. Acrescente-se que essa integração na modalidade EJA confere ao curso Proeja/MSI uma complexidade diferente da dos demais cursos do campus. Tal análise encontra eco na fala do professor Hórus:

[...] acho que as coisas poderiam ser reformatadas para que esses diálogos acontecessem mais, mas para isso teria que ver carga horária, espaço, né; professores dedicados ao curso sim, porque a gente vê que todo período muda um professor de repente agora; o professor de Química agora não é mais o do período passado, entrou um outro, no outro período entra um outro e aí a gente acaba não tendo uma continuidade no diálogo... (1/6/2017).

Hórus expressa seu pensamento sobre a possibilidade de os professores se dedicarem ao curso da seguinte forma:

[...] seria muito melhor, todos, é, se falariam mais, o entendimento seria muito mais rápido [...] do que você ter uma outra pessoa nova que entra, até ela aprender leva tempo e quando ela aprende, ela sai fora, né, é quase com que um professor substituto, o professor substituto fica dois anos, e aí, quando ele está engajado nos projetos, ele está bem antenado, sai, entra um outro que vai começar o processo todo de novo (1\%/6/2017).

Ao mesmo tempo ele fez o que designou de "desabafo". Enquanto há professores que permanecem por anos no mesmo curso técnico ou nos cursos superiores, o mesmo não ocorre quando se trata do curso Proeja/MSI:

[...] quando você fala no MSI, isso já não acontece porque, e aí, vai um desabafo, tá, não sei se você vai usar ou não, mas os professores não querem dar aula no MSI; então, para complementar carga horária eles vão para o MSI e a gente vê que tem professor que está no MSI que não tem, é, comprometimento algum com esse 
tipo pedagógico de ser e isso acaba prejudicando, porque toda aquela sintonia que deveria existir a cada semestre alguns professores entram e acabam com essa sintonia (1\%/6/2017).

O professor Eugênio nos ofereceu uma inesperada exposição de ideias sobre o PI. Ele iniciou nos falando da sua compreensão do que seria a Pedagogia de Projetos. Para desenvolver um projeto, alguns parâmetros devem ser seguidos, porque numa turma "não vai ter um projeto que todos vão querer exatamente, então, é um consenso, na qual [sic] acho que o professor, embora ele tenha um peso grande, e esse que é o segredo, ele tem que ter influência" (Prof. Eugênio, 5/6/2017). Um dos parâmetros é procurar mostrar aos estudantes que os projetos não podem perder de vista a área técnica do curso e os diversos conhecimentos necessários à formação de nível médio. 0 ponto marcante de sua exposição foi o questionamento sobre os eixos temáticos, ${ }^{9}$ que ele enunciou da seguinte forma:

[...] é um projeto sem viés, isso eu nem me lembro de onde tiraram, mas eu briguei tanto... Os eixos, jamais respeitei esses eixos, jamais no meus $\mathrm{PI}$, nem queria saber qual era o eixo, porque eu acho que [...] o que interessa: qual é o projeto, eu vou resolver que problema, chegamos à conclusão de que todos eles estão com problema de instalação elétrica em casa, então, vamos resolver esse problema, agora, é claro que não é uma resolução de um problema só na Física "Por que é que vocês têm instalação, a instalação é ruim nas casas de vocês? Por que que lá tem gato e não tem? Onde é que vocês estão morando?" Historicamente, sabe, você tem um montão... de pegar uma situação e abordar "Ó, vamos o resolver" e "Por que que lá vocês não conseguem NET?", tá certo, por que que a NET não vende lá? Porque sabe, aí, você vai para o outro lado. Problema social, então, você pode ter um problema que você vai resolver e abordar...[...] (5/6/2017).

Eugênio nos fornece um exemplo de tratar o concreto real por meio das ideias para, então, chegar ao real criticado com o objetivo de sua transformação (SAVIANI, 2013).

Por essa forma de pensar, foi possível entender que o professor Eugênio propôs mudar o paradigma da organização em disciplinas, pois, na medida em que o problema a resolver fosse definido, os professores reuniriam-se e discutiriam o que, dentro dos conhecimentos necessários de serem assimilados pelos estudantes, seria agregado ao projeto para resolver o problema. O pensamento de Eugênio aproxima-se da proposta do Plano de Curso (IFRS-BG, 2010) que enuncia que "o tema gerador não é algo pronto; é construído para cada turma, e é o ponto de partida para a elaboração do conteúdo programático" (ESCANDIEL CRIZEL; GREFF PASSOS; DEL PINO, 2014, p. 71). Segundo Eugênio, ao longo dos períodos do curso todos os projetos desenvolvidos seriam registrados numa espécie de "caderneta", para que fosse possível identificar os conhecimentos que ainda precisariam ser vistos em futuros projetos.

Ele nos contou que estabeleceu um debate na equipe sobre a organização da Pedagogia de Projetos em eixos temáticos, mas ouviu os seguintes argumentos:

Eixo para 1ำ período: o aluno inserido em sua casa; eixo para 2 período: o aluno inserido em sua comunidade; eixo para 3 o período: o aluno inserido na sociedade; eixo para 4ㅇ e 5o períodos: o aluno inserido no mercado de trabalho. 
"Não, vamos enquadrar para o Proeja ser bem feito aqui", começar a enquadrar na escola, entendeu, quando eu achava que devia desenquadrar na escola, [...] para ter um laboratório desse tem que ter alguma coisa, para os outros professores verem o Proeja de maneira respeitosa, o Proeja tinha que ter um G1, um G2, ${ }^{10}$ sabe, então, no fim é uma visão, né, para os alunos se sentirem bem que o curso deles é bem, né, a gente não conseguiu vender "Olha, o curso de vocês vai ser mal falado mas é o melhor, e é nisso que nós vamos lutar", não foi, foi enquadrar [...] (5/6/2017).

Ele conseguiu lembrar-se que a proposta do Proeja previa a possibilidade de uma organização espaço-temporal diferente, com o objetivo de atender às especificidades dos sujeitos da EJA e da formação integrada.

\section{CONCLUSÕES}

As reflexões do professor Eugênio trouxeram a possibilidade de estabelecer a relação das escolhas e das formas de ensino realizadas pelos professores com a proposta pedagógica do curso Proeja/MSI, e remeteram à afirmação do coordenador do curso: "eu tenho certeza que, é, cada um dos professores arrumou uma estratégia para trabalhar. Estão faltando as reuniões de professores, para gente trocar essas ideias" (Em 23/6/2017). Esta afirmação corrobora a ideia de que a organização pedagógica da instituição é complexa, seja pelas áreas de conhecimento, seja pelos objetivos de cada curso. Para lidar com tal complexidade, enxergamos o "desafio de conviver (falar e ouvir) com linguagens e saberes diferentes" (PIMENTA, 1999, p. 16) dos diversos campos específicos. Em se tratando de um curso que tem como concepção a Pedagogia de Projetos, esse desafio parece ser especialmente importante para o trabalho interdisciplinar e coletivo no curso.

Para o professor Eugênio, a integração curricular existia, nos anos 90 do século 20, antes do decreto que separava a formação técnica da geral (ensino propedêutico), se considerarmos que as ementas da sua disciplina listavam conteúdos que iriam "ajudar" as disciplinas técnicas dos períodos adiante. O mesmo professor Eugênio, porém, afirma: "isso nunca aconteceu demais aqui não, os professores de Física sempre achavam que sabiam o que tinham que ensinar".

Em 2015, durante uma reunião que discutia o fim da modalidade EJA, uma referência à integração curricular entre a formação geral e a formação técnica, feita por um professor substituto, suscitou duas respostas. A primeira dizia que a integração curricular seria impossível e a segunda que determinada disciplina não queria ser ferramenta, uma vez ser ciência. Ambas as respostas causam estranhamento, posto que o modelo pedagógico praticado, baseado na pedagogia de projetos, é considerado uma possibilidade de materialização do currículo integrado (ARAÚJO; FRIGOTTO, 2015).

A investigação evidenciou que o trabalho do professor no IFRJ não está submetido a controle institucional, ocasionando perda de autonomia do docente. Sendo assim, ao encontro do que nos diz o professor Hórus a respeito da necessidade de os diálogos

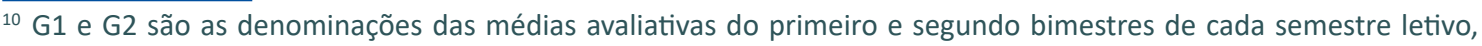
respectivamente.
} 
serem mais frequentes, existe condição favorável para o aprofundamento das discussões sobre a materialização do currículo integrado e sobre a contradição, sinalizada pelo professor Eugênio, relacionada à decisão de "enquadrar" o Proeja/MSI no formato dos demais cursos.

Os relatos dos professores evidenciaram que a prática pedagógica concreta pode tornar os projetos integradores, com uma possibilidade de materialização do currículo integrado.

A Pedagogia de Projetos, escolhida para embasar o projeto político-pedagógico do Proeja/MSI, é um tema que pode ser aprofundado em pesquisas futuras como forma de contribuir com a produção acadêmica já existente sobre as possibilidades de materialização do EMI.

Considerando que a integração se dá na modalidade EJA, toda contribuição teórico-prática é importante e necessária para alimentar o diálogo entre as diversas áreas de conhecimento para fazer frente à complexidade dessa modalidade da educação básica.

A investigação empreendida representou uma reunião interdisciplinar, perdida no tempo por inúmeras razões, mas que, se retomada, pode socializar ideias e proporcionar troca e produção de conhecimento.

As entrevistas possibilitaram, aos professores, reflexões sobre suas próprias experiências. Tais experiências são pessoais e se limitam à sala de aula. Reuniões interdisciplinares, porém, podem construir um repertório de saberes da ação pedagógica no sentido de contribuir para a fundamentação teórico-prática do currículo integrado.

\section{REFERÊNCIAS}

ALVES, C. M. C. Problemas da relação educação - cidadania na história brasileira. In: FELGUEIRAS, M. L.; VIEIRA, C. E. (org.). Cultura escolar, migrações e cidadania. Porto, 2010. p. 145-162.

ALVES, T. Currículo e Interdisciplinaridade no Projeto Político-Pedagógico do PROEJA. Revista Exitus, Santarém, PA, v. 8, n. 1, p. 224-249, jan./abr. 2018a. Disponível em: http://www.ufopa.edu.br/portaldeperiodicos/index.php/revistaexitus/article/view/396. Acesso em: 15 mar. 2018.

ALVES, T. Saberes e fazeres dos professores: a educação profissional técnica de nível médio, na modalidade Educação de Jovens e Adultos. Orientadora: Maria Cecilia Castello Branco Fantinato. 2018b. 288 f. Tese (Doutorado em Educação) - Faculdade de Educação, Universidade Federal Fluminense, Niterói, $2018 \mathrm{~b}$.

ALVES, T.; SOUZA DE ALMEIDA, E.; ALMEIDA, R. A. Relato de experiência sobre o desenvolvimento de um projeto integrador: exercitando o confronto de ideias. In: SOBRINHO, S. C.; PLÁCIDO, R. L.; RIBEIRO, R. Q. W. (org.). Os "Nós" que fortalecem a Rede Federal de Educação Profissional, Científica e Tecnológica: experiências e expertises nos/dos Institutos Federais. Blumenau: IFC, 2019. p. 16-20. Disponível em: http:// editora.ifc.edu.br/2019/12/10/os-nos-que-fortalecem-a-rede-federal-de-educacao-profissional-cientifica-e-tecnologica/. Acesso em: 19 abr. 2020.

ARAÚJO, R. M. de L.; FRIGOTTO, G. Práticas pedagógicas e ensino integrado. Revista Educação em Questão, v. 52, n. 38, p, 61-80, maio/ago. 2015.

BARDIN, L. Análise de conteúdo. Trad. Luís Antero Reto e Augusto Pinheiro. São Paulo: Edições 70, 2016.

BLUM, M. S. R.; ZANARDINI, I. M. S. A Reforma da Educação Básica implementada na década de 1990 e o PROEJA: reflexões sobre convergências e divergências. In: SILVA, M. R. S; AMORIM, M. L.; VIRIATO, E. O. (org.). Proeja - Educação Profissional integrada à EJA: entre políticas e práticas. Curitiba: Ed. UTFPR, 2011. p. 195-217.

BOGDAN, R. C.; BIKLEN, S. K. Investigação qualitativa em educação. Porto: Porto Editora, 1994.

BOURDIEU, P. A escola conservadora: as desigualdades frente à escola e à cultura. In: NOGUEIRA, M. A.; CATANI, A. M. (org.). Escritos da educação. 16. ed. Petrópolis, RJ: Vozes, 2015. p. 45-72. (Coleção Ciências Sociais da Educação). 
BRASIL. CEFETEQ/RJ. Diretoria de Ensino Médio Técnico. Projeto Político-Pedagógico do Curso PROEJA/ MSI. Nilópolis, jul. 2007.

CIAVATTA, M.; RAMOS, M. A "era das diretrizes": a disputa pelo projeto de educação dos mais pobres. Rev. Bras. Educ., Rio de Janeiro, v. 17, n. 49, p. 11-37, jan./abr. 2012. Disponível em: http://www.scielo. $\mathrm{br} / \mathrm{scielo}$.php?script=sci_arttext\&pid=S1413-24782012000100002\&lng=en\&nrm=iso. Acesso em: 26 dez. 2017.

DELORS, J. et al. Educação: um tesouro a descobrir. Relatório para a UNESCO da Comissão Internacional sobre Educação para o século XXI. Trad. Guilherme João de Freitas Teixeira. Brasília: Unesco, 2010. Disponível em: http://unesdoc.unesco.org/images/0010/001095/109590por.pdf. Acesso em: 26 dez. 2017.

DE VARGAS, S.; FANTINATO, M. C. C. B. Formação de professores da educação de jovens e adultos: diversidade, diálogo, autonomia. Revista Diálogo Educacional, v. 11, n. 34, p. 915-931, set./dez. 2011.

DI PIERRO, M. C.; JOIA, O.; RIBEIRO, V. M. Visões da educação de jovens e adultos no Brasil. Cadernos Cedes, Campinas, São Paulo, v. 21, n. 55, p. 58-77, 2001. Disponível em: http://www.scielo.br/scielo.php?scrip$\mathrm{t}=$ sci_arttext\&pid=S010132622001000300005\&lng=en\&tIng=pt. $\quad 10.1590 / \$ 0101-32622001000300005$. Acesso em: 18 ago. 2015.

DI PIERRO, M. C. Educação de Jovens e Adultos no Brasil: questões face às políticas públicas recentes. Em Aberto. v. 11, n. 56, p. 22-30, out./dez. 1992.

ESCANDIEL CRIZEL, L.; GREFF PASSOS, C.; DEL PINO, J. O Currículo Integrado do PROEJA do IFRS - Campus Bento Gonçalves: Uma possibilidade real e complexa de efetivação em sala de aula. Revista Contexto \& Educação, v. 28, n. 91, p. 58-83, 14 set. 2014. Disponível em: https://www.revistas.unijui.edu.br/index. php/contextoeducacao/article/view/1431. Acesso em: 19 abr. 2020.

FÁVERO, O.; RUMMERT, S.; DE VARGAS, S. Formação de profissionais para a educação de jovens e adultos trabalhadores. Educação em Revista, Belo Horizonte, n. 30, p. 39-49, 1999.

FERNANDES, F. Depoimento. In: MEDEIROS, P. M. (org.). Florestan Fernandes: memória viva da educação brasileira. Brasília: MEC; INEP, 1991.

FONSECA, M. C. F. R. A inserção da educação matemática no processo de escolarização básica de pessoas jovens e adultas. In: ENCONTRO NACIONAL DE EDUCAÇÃO MATEMÁTICA, 6., 1998. Anais... São Leopoldo: SBEM, 1998. Disponível em: http://www.sbembrasil.org.br/sbembrasil/index.php/anais. Acesso em: 17 maio 2018.

FONSECA, M. C. F. R. Educação matemática de jovens e adultos. Belo Horizonte: Autêntica, 2002.

FREIRE, P. Pedagogia da indignação: cartas pedagógicas e outros escritos. São Paulo: Editora Unesp, 2000. FRIGOTTO, G. Ensino médio e educação profissional: a ruptura com o dualismo estrutural. [Entrevista cedida a] Luiz Fernandes Dourado. Retratos da Escola, Brasília, v. 5, n.8, p. 11-24, jan./jun. 2011. Disponível em: http://www.cnte.org.br/images/stories/retratos_da_escola/retratos_da_escola_08_2011.pdf. Acesso em: 2 nov. 2017.

FRIGOTTO, G.; CIAVATTA, M.; RAMOS, M. Apresentação. In: FRIGOTTO, G.; CIAVATTA, M.; RAMOS, M. (org.). Ensino Médio integrado: concepção e contradições. São Paulo: Cortez, 2005. p. 7-20.

FRIGOTTO, G.; CIAVATTA, M.; RAMOS, M. A gênese do Decreto no 5154/2004: um debate no contexto controverso da democracia restrita. In: FRIGOTTO, G.; CIAVATTA, M.; RAMOS, M. Ensino Médio integrado: concepção e contradições. São Paulo: Cortez, 2005. p. 21-56.

FRIGOTTO, G.; CIAVATTA, M. Perspectivas sociais e políticas da formação de nível médio: avanços e entraves nas suas modalidades. Revista Educação \& Sociedade, Campinas, São Paulo, v. 32, n. 116, p. 619-638, jul./set. 2011.

JULIÃO, E. F. Os sujeitos da educação de jovens e adultos: questões sobre a diversidade. 2012. 18 slides. Disponível em: http://portal.mec.gov.br/arquivos/conferencia/documentos/elionaldo_juliao.pdf. Acesso em: 19 nov. 2017.

KAUFMANN, J. C. A entrevista compreensiva: um guia para pesquisa de campo. Trad. Thiago Abreu e Lima Florencio. Petrópolis: Vozes; Maceió: Edufal, 2013.

KUENZER, A. Z.; GRABOWSK, G. A produção do conhecimento no campo da educação profissional no regime de acumulação flexível. Holos, Natal, 2016. v. 6, p. 22-32. Disponível em: http://dx.doi.org/10.15628/ holos.2016.4983. Acesso em: 2 jul. 2018.

KUENZER, A. Z. O Ensino Médio agora é para a vida: entre o pretendido, o dito e o feito. Educ. Soc. [on-line]. 2000, v. 21, n. 70, p. 15-39, ISSN 0101-7330. Disponível em: http://dx.doi.org/10.1590/S010173302000000100003. Acesso em: 2 jul. 2018. 
MACHADO, M. M. A trajetória da EJA na década de 90: políticas públicas sendo substituídas por solidariedade. In: REUNIÃO ANUAL DA ANPED, 21., 1998, Caxambu. Disponível em: http://forumeja.org.br/gt18/ files/MACHADO.pdf_2_0.pdf. Acesso em: 28 de out. 2017.

PIMENTA, S. G. Formação de professores: identidade e saberes da docência. In: PIMENTA, S. G. (org.). Saberes pedagógicos e atividade docente. São Paulo: Cortez Editora, 1999. p. 15-34.

RAMOS, M. O currículo para o Ensino Médio em suas diferentes modalidades: concepções, propostas e problemas. Educação \& Sociedade, Campinas, São Paulo, v. 32, n. 116, p. 771-788, jul./set., 2011.

RAMOS, M. Possibilidades e desafios na organização do currículo integrado. In: FRIGOTTO, G.; CIAVATTA, M.; RAMOS, M. (org.). Ensino Médio integrado: concepção e contradições. São Paulo: Cortez, 2012. p. 107-127.

ROMÃO, J. E. Educação de Jovens e Adultos: problemas e perspectivas. In: GADOTTI, M.; ROMÃO, J. E. (orgs.). Educação de Jovens e Adultos: teoria, prática e proposta. 12. ed. São Paulo: Cortez, 2011. p. 48-68. SAVIANI, D. Educação: do senso comum à consciência filosófica. 19. ed. Campinas, SP: Autores Associados, 2013.

VENTURA, J. A trajetória histórica da educação de jovens e adultos trabalhadores. In: TIRIBA, L.; CIAVATTA, M (orgs.). Trabalho e Educação de Jovens e Adultos. Brasília: Líber Livro; Niterói: Editora UFF, 2011. p. 5797. 